\title{
Seasonal variations of storm-time TEC at European middle latitudes
}

\author{
S. M. Stankov ${ }^{*}$, K. Stegen, R. Warnant \\ Royal Meteorological Institute (RMI), Ringlaan 3, B-1180 Brussels, Belgium \\ *Corresponding author. Tel.: +32 60395 472; Fax: +32 60395 423; E-mail: S.Stankov@meteo.be
}

\begin{abstract}
Global Navigation Satellite System (GNSS) measurements of the Total Electron Content (TEC) from local (Dourbes, $50.1^{\circ} \mathrm{N}, 04.6^{\circ} \mathrm{E}$ ) and European IGS (International GNSS Service) stations were used to obtain the TEC changes during the geomagnetic storms of the latest solar activity cycle. A common epoch analysis, with respect to geomagnetic storm intensity, season, and latitude, was performed on data representing nearly 300 storm events. In general, the storm-time behaviour of TEC shows clear positive and negative phases, relative to the non-storm (median) behaviour, with amplitudes that tend to increase during more intense storms. The most pronounced positive phase is observed during winter, while the strongest and yet shortest negative phase is detected during equinox. Average stormtime patterns in the TEC behaviour are deduced for potential use in ionosphere prediction services.
\end{abstract}

Keywords: ionosphere, geomagnetic storm, TEC, GNSS

\section{Introduction}

Ever since the advent of satellite navigation technology and applications, there has been a growing interest in further understanding and accurately modelling the TEC (Total Electron Content) behaviour. TEC is a robust parameter that can be utilised, on the one hand, for studying the ionosphere-plasmasphere system and, on the other hand, for providing much needed information for GNSS (Global Navigation Satellite System) - based positioning accuracy/correction.

The climatology of the ionospheric electron content has been studied recently (Afraimovich et al., 2006; Astafyeva et al. 2008; Hocke, 2008; Liu et al., 2009) with the help of the IGS (International GNSS Service) ionospheric maps. Thus, the ionospheric response to solar activity, and the ionospheric dynamics in general, were tracked on a global scale over a complete solar cycle. The introduced Global Electron Content (GEC) and the Global Mean TEC (GMTEC) quantities seem to capture the global characteristics of the ionospheric dynamics reasonably well. GEC was found to satisfactorily represent the solar activity level and the 27-day variations of GEC look similar to the F10.7 index variations (albeit with a time lag of 30 to 60 hours). GMTEC fluctuates with strong eleven-year, annual, semiannual, and 27-day periodicity. Both, the hemispheric differences and the annual asymmetry in the mean TEC tend to be more pronounced at higher solar activity. Also, solar flares can cause high-frequency perturbations and TIDs (Travelling Ionospheric Disturbances) may generate substantial amplitude fluctuations in TEC.

The TEC response to the ever present geomagnetic activity constitutes a large portion of the overall TEC variability. Although the 'background' level of geomagnetic activity $(\mathrm{Kp}<4)$ is known to influence the TEC behaviour (Jodogne and Stankov, 2002), it is the geomagnetic forcing during storms that is of particular interest for us here. Since the GNSS trans-ionospheric signal delay varies substantially during ionosphere perturbed conditions and may lead to increased positioning errors, the knowledge of the storm-time TEC behaviour is becoming of utmost significance (e.g. Stankov et al., 2006, 2007, 2009; Warnant et al., 2007; and the references therein). A strong relationship exists between geomagnetic storms and ionospheric perturbations. Past studies have led to a better understanding of this relationship and it is now clear that, at middle latitudes, the ionospheric storms go through an initial 'positive' phase, when the electron density and the electron content are greater than the normal (median) values, followed by the main 'negative' phase when the abovementioned quantities are reduced below their normal pre-event values (Hargreaves, 1992; Araujo-Pradere et al., 2006). There are, however, differences from storm to storm, and certain storm characteristics, such as 
longevity, positive/negative disturbances, and propagation of the storm-induced effects, can substantially vary depending on latitude, season, local time, etc. (Akasofu and Chapman, 1972; Mendillo, 1973; Proelss, 1984, 1995; Gonzalez et al., 1994; Fuller-Rowell et al., 1996; Ho et al., 1996; Buonsanto, 1999). Although it is true that each storm has its individual characteristics, there are evidences that some common/consistent storm-time features can be deduced from detailed statistical analyses (Ho et al., 1996, 1998; Fuller-Rowell et al., 1996; Kutiev and Muhtarov, 2001; AraujoPradere et al., 2006; Mannucci et al., 2008).

The objective of this paper is to present a study of the seasonal behaviour of TEC during the geomagnetic storms within the years 1994-2009 at European middle latitudes. For this purpose, GNSS measurements from local, Belgian, and other European IGS stations were used to obtain the TEC storm-time changes. Data representing nearly 300 storm events was processed and analysed with consideration to geomagnetic storm intensity, season, and latitude. This is a continuation of our previous work towards providing more reliable TEC modelling and forecasting service for GNSS users (Stankov et al., 2004, 2006, 2007; Stankov and Jakowski, 2006; Warnant et al., 2007).

The paper is organised as follows. In the next section 2, the Dst and TEC measurements are described together with the method of analysis. In section 3, we present the observations at a midlatitude $\left(50^{\circ} \mathrm{N}\right)$ location followed by observations in the mid-latitudinal range $\left(30^{\circ} \mathrm{N}-60^{\circ} \mathrm{N}\right)$ and, for a better perspective, in the high-latitude range of $60^{\circ} \mathrm{N}-80^{\circ} \mathrm{N}$. The results are discussed in section 4 together with factors contributing to the persistent TEC features during storms. The paper concludes with a summary of the observations and an outlook to further studies and possible applications.

\section{Data base and method of analysis}

For the purpose of this study we consider all geomagnetic storms that occurred between January 1994 and December 2009, i.e. including the entire solar cycle 23. The main reference when selecting a storm period is the Dst geomagnetic index (Sugiura, 1964; Akasofu and Chapman, 1972), measuring the strength of the ring current and used for representing the geomagnetic storm intensity (activity level). During the storm onset phase, the Dst increases to a maximum (positive) value and then, during the storm main phase it decreases to a minimum (negative) value which marks the end of the main phase and the beginning of the recovery phase when Dst returns to its pre-storm values. For a period to be considered as a storm period and to be included in our analysis, Dst should fall below -50 nT for at least 1 hour during that period.

The storm time (ST) begins with the storm onset. The storm onset is relatively easy to determine for storms with sudden storm commencement (SSC), however there are many storms with gradual commencement or storms that occur during the recovery phase of another storm. Here, for the SSC storms, the onset is set at the moment of the Dst peak and, for the non-SSC storms, at the moment just before a persistent decrease in Dst. In all cases the Dst minimum should be reached within 36 hours. If a period of increased geomagnetic activity shows multiple Dst minima, we assign these to separate storm events provided that the two minima are separated by at least 24 hours.

For statistical purposes it is essential to have a large sample size, therefore all eligible storm events are accounted for. The selected storms are classified according to their intensity (Fig.1) using the standard nomenclature: Class II ("moderate", Dst minimum between -100 nT and -50 nT) and Class I ("intense", Dst minimum $\leq-100 \mathrm{nT}$ ). In addition, we introduc the "extreme" storm class, Class $\mathrm{X}$ (Dst minimum $\leq-200 \mathrm{nT}$ ), which is in fact a sub-class of Class I. As noted in the introduction, the ionospheric response to geomagnetic storms depends heavily on season. From this aspect, three seasons (winter, summer, and equinox) are defined as 91-day periods centred on the (North hemisphere) winter solstice (day of year, DoY 356), summer solstice (DoY 173) and equinoxes (DoY 81 and DoY 264).

Based on the above-described selection and classification criteria, 298 geomagnetic storms were identified between January 1994 and December 2009 (final Dst values were used through December 2003 and provisional Dst values since then). The storm occurrence is summarised in Table 1. The occurrence was lowest at the recent solar minimum (2006-2009). The majority of storms occurred in the equinox periods (vernal 29\%, autumn 30\%), followed by winter $(22 \%)$ and summer $(19 \%)$. Extreme storms occurred mainly $(69 \%)$ in the equinox periods, no such storms were observed during solar minima. 

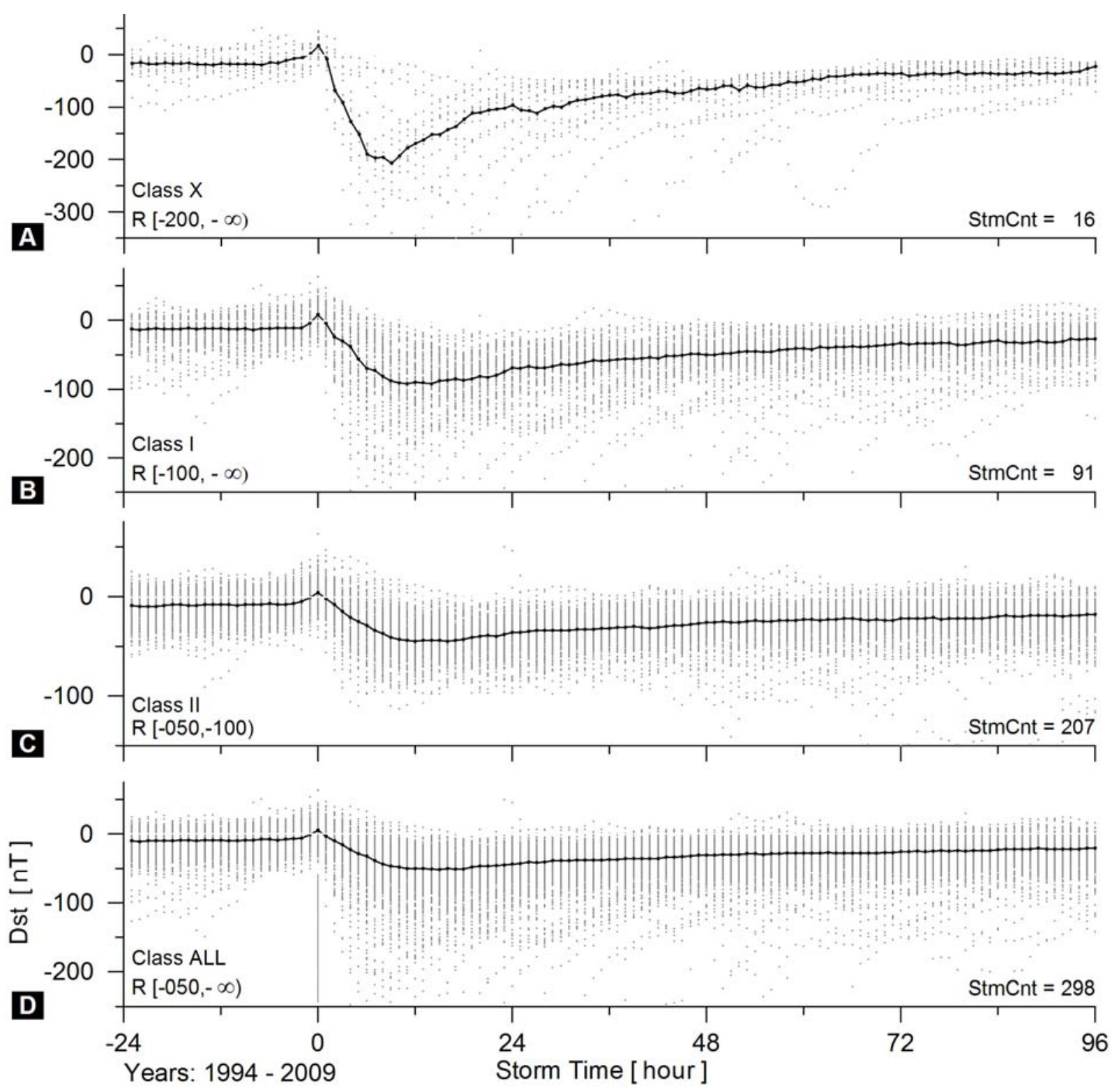

Fig.1. Superposed Dst index variations during the geomagnetic storms within the years 1994-2009. Dst hourly values (grey dots) and medians (solid black dots) plotted against storm time: for storms of all classes together (bottom panel D), class II (panel C), class I (panel B), and class X (top panel A).

Local TEC observations have been made with GPS (Global Positioning System) receivers at the RMI Geophysical Centre in Dourbes $\left(50.1^{\circ} \mathrm{N}, 04.6^{\circ} \mathrm{E}\right)$ applying a computational procedure based on the 'geometry-free' combination of the GPS code and phase measurements for resolving the ambiguities. Receiver and satellite group delays are estimated by modelling the slant TEC with a simple polynomial (depending on latitude and local time) and conversion to vertical TEC was performed by assuming the standard ionospheric thin-shell model at a mean ionospheric height of 350 km (Warnant, 1998; Warnant and Pottiaux, 2000; Hofmann-Wellenhof et al., 2008). To obtain a TEC value that is representative of the ionosphere above the given location and time, selected and averaged are all values within the latitudinal range of $\pm 1.5^{\circ}$ in the preceding 15 -minute period. The TEC database consists of measurements since July 1994, i.e. covering more than one complete solar cycle period. Vertical TEC data, retrieved from the CODE (Centre for Orbit Determination in Europe) global ionosphere maps (GIM) generated from IGS (International GNSS Service) measurements (Schaer et al., 1996; Schaer, 1999; Beutler et al., 1999; Hernandez-Pajares et al., 2009), are also utilized for additional reference and for deducing the latitudinal dependence of storm-time variations. 


\begin{tabular}{|c|c|c|c|c|c|c|c|c|c|c|c|c|}
\hline \multirow{3}{*}{$\begin{array}{r}\begin{array}{r}\text { CCYY } \\
\text { (F10.7 } \\
\text { obs.1-y mean) }\end{array} \\
\text { DoY } \\
\text { class } \\
\end{array}$} & $\begin{array}{l}\text { WN-1 } \\
\text { (winter) }\end{array}$ & \multicolumn{2}{|c|}{$\begin{array}{l}\text { EQX-V } \\
\text { (vernal } \\
\text { equinox) } \\
\end{array}$} & \multicolumn{2}{|c|}{$\begin{array}{c}\text { SUM } \\
\text { (summer) }\end{array}$} & \multicolumn{2}{|c|}{$\begin{array}{c}\text { EQX-A } \\
\text { (autumn } \\
\text { equinox) }\end{array}$} & \multicolumn{2}{|c|}{$\begin{array}{l}\text { WN-2 } \\
\text { (winter) }\end{array}$} & \multicolumn{2}{|c|}{$\begin{array}{l}\mathrm{I}^{\prime}(\mathrm{X})^{\text {Total }} \\
\text { II }\end{array}$} & \multirow[t]{2}{*}{$\begin{array}{c}\text { Total } \\
\text { I+II }\end{array}$} \\
\hline & $001-035$ & $036-12$ & & $128-2$ & & $219-3$ & & $311-36$ & $65 / 6$ & & & \\
\hline & $I(X) \quad I I$ & $I(X)$ & II & $I(X)$ & II & $I(X)$ & II & $I(X)$ & II & $I(X)$ & II & $1+\|$ \\
\hline $\begin{array}{c}1994 \\
(85.8)\end{array}$ & 0 & 5 & 4 & 0 & 2 & 1 & 4 & 1 & 1 & 7 & 11 & 18 \\
\hline $\begin{array}{c}1995 \\
(71.6) \\
\end{array}$ & 0 & 2 & 7 & 0 & 4 & 2 & 6 & 0 & 3 & 4 & 22 & 26 \\
\hline $\begin{array}{l}1996 \\
(72.0)\end{array}$ & 0 & 0 & 4 & 0 & 0 & 1 & 2 & 0 & 0 & 1 & 7 & 18 \\
\hline $\begin{array}{c}1997 \\
(81.0)\end{array}$ & 1 & 1 & 7 & 1 & 2 & 1 & 4 & 2 & 3 & 5 & 17 & 22 \\
\hline $\begin{array}{c}1998 \\
(118.1)\end{array}$ & 0 & $3(1)$ & 4 & 2 & 3 & $3(1)$ & 6 & 3 & 2 & $11(2)$ & 17 & 28 \\
\hline $\begin{array}{c}1999 \\
(153.8)\end{array}$ & 1 & 2 & 3 & 0 & 3 & $2(1)$ & 7 & 0 & 2 & $5(1)$ & 16 & 21 \\
\hline $\begin{array}{c}2000 \\
(179.9)\end{array}$ & 2 & $2(1)$ & 3 & $2(1)$ & 5 & $6(2)$ & 6 & 2 & 3 & $12(4)$ & 19 & 31 \\
\hline $\begin{array}{c}2001 \\
(181.4)\end{array}$ & 1 & $5(2)$ & 5 & 0 & 2 & $5(1)$ & 6 & 1(1) & 2 & $11(4)$ & 16 & 27 \\
\hline $\begin{array}{c}2002 \\
(179.5)\end{array}$ & 0 & 2 & 3 & 3 & 3 & 4 & 3 & 1 & 5 & 10 & 16 & 26 \\
\hline $\begin{array}{c}2003 \\
(128.5)\end{array}$ & 3 & 0 & 7 & 2 & 8 & $2(1)$ & 6 & 1(1) & 2 & $5(2)$ & 26 & 31 \\
\hline $\begin{array}{c}2004 \\
(106.5)\end{array}$ & 1 & 2 & 2 & 3 & 1 & 1 & 2 & 1(1) & 3 & $8(1)$ & 10 & 18 \\
\hline $\begin{array}{l}2005 \\
(91.7)\end{array}$ & 2 & 1 & 5 & $4(1)$ & 4 & $3(1)$ & 2 & 0 & 2 & $10(2)$ & 15 & 25 \\
\hline $\begin{array}{l}2006 \\
(80.0)\end{array}$ & 0 & 1 & 2 & 0 & 0 & 0 & 2 & 1 & 2 & 2 & 6 & 8 \\
\hline $\begin{array}{l}2007 \\
(73.1)\end{array}$ & 0 & 0 & 2 & 0 & 1 & 0 & 1 & 0 & 1 & 0 & 5 & 5 \\
\hline $\begin{array}{l}2008 \\
(69.0)\end{array}$ & 0 & 0 & 1 & 0 & 0 & 0 & 2 & 0 & 0 & 0 & 3 & 3 \\
\hline $\begin{array}{c}2009 \\
(70.6) \\
\end{array}$ & 0 & 0 & 0 & 0 & 1 & 0 & 0 & 0 & 0 & 0 & 1 & 1 \\
\hline Total & $4(0) \quad 19$ & 26(4) & 59 & $17(2)$ & 39 & 31(7) & 59 & $13(3)$ & 31 & 91(16) & 207 & 298 \\
\hline
\end{tabular}

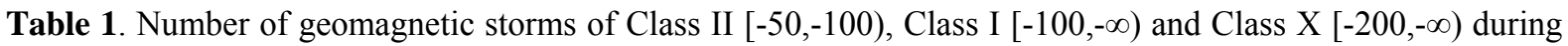
the winter, equinox, and summer periods of 1994-2009. The nominal start of the storms determines the belonging to a particular season. The observed 1-year mean values of F10.7 is given in the brackets below the corresponding year. The number of X-class storm is given in brackets after the number of I-class storm.

When analysing TEC variations during geomagnetic storms, it is preferable to use the relative deviation $\left(\mathrm{TEC}_{\mathrm{rel}}\right)$ of the observed TEC $\left(\mathrm{TEC}_{\mathrm{obs}}\right)$ from normal (non-disturbed) conditions reference TEC (in this study, the 27-day running median, $\mathrm{TEC}_{\mathrm{med}}$, for each hour of the day): $T E C_{r e l}=\left(T E C_{o b s}-T E C_{m e d}\right) / T E C_{\text {med }}$. Since the median represents (by reducing the importance of possible outliers) the most likely value over a pre-defined period, the $\mathrm{TEC}_{\mathrm{rel}}$ values during a geomagnetic storm reflect mostly the instantaneous changes in TEC due to the storm. Also, $\mathrm{TEC}_{\mathrm{rel}}$ is a dimensionless quantity (a number without any physical units) which makes it suitable for comparing and analysing data collected from different geomagnetic storms. Further on, to correctly deduce the average storm-time changes in the $\mathrm{TEC}_{\mathrm{rel}}$ behaviour, a superposed epoch analysis is carried out for the selected storm periods (for which TEC data is available) from years 1994 through 2009, with respect to both, season and storm intensity. 


\section{Observation results}

First we present the results for the location of Dourbes. The instantaneous Dst and TEC measurements are arranged according to the storm onset $(\mathrm{ST}=0)$ and the corresponding hourly medians (with reference to each storm time hour) of Dst and $\mathrm{TEC}_{\text {rel }}$ are shown in Fig.2. The vertical axis corresponds to the Dst index (solid curve) and the relative percentage of TEC (vertical bars). The horizontal axis is the storm time (in hours), ranging from -24ST (i.e. 24 hours before the start) through +96ST (i.e. 96 hours after the start). The left panel shows the results from class I storms and the right panel contains the results from class II storms. The summer results are plotted on the top, equinox in the middle, and winter - at the bottom.

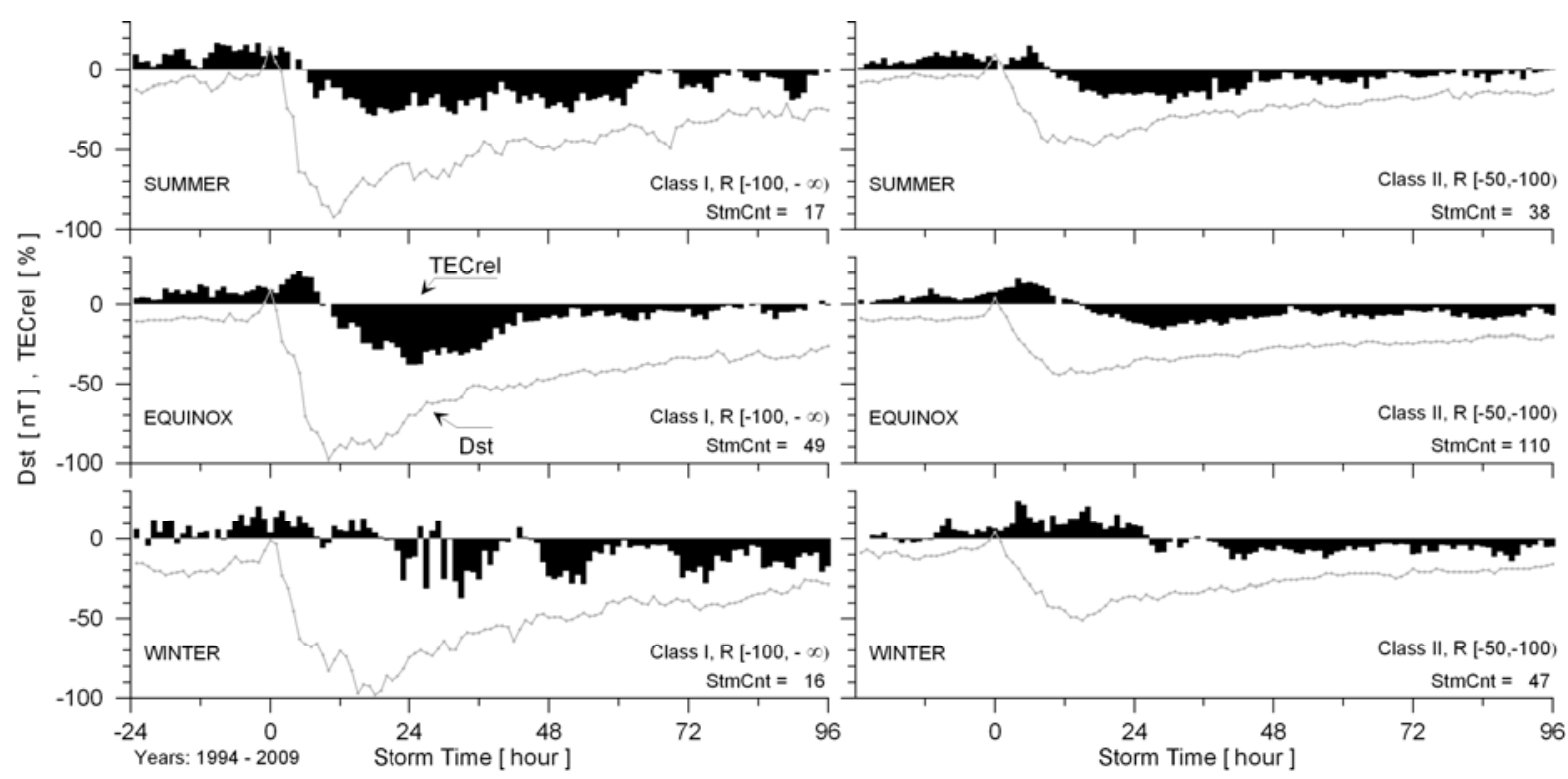

Fig.2. GPS TEC relative deviations $\left(\mathrm{TEC}_{\mathrm{rel}}\right)$ from 27-day medians during geomagnetic storms of class I (left panels) and class II (right panels) in summer (top), equinox (middle), and winter (bottom) for the site of the IGS station DOUR $\left(4.6^{\circ} \mathrm{E}, 50.1^{\circ} \mathrm{N}\right)$ based on data from the $1994-2009$ period.

The median $\mathrm{TEC}_{\text {rel }}$ response shows obvious similarities as well as differences at different storm times and seasons. With reference to storm time, the TEC percentage deviation increases during the onset phase, peaks around $\mathrm{ST}=0$, and then decreases during the main phase to consequently form a long-lived depression during the recovery phase. In fact, the $\mathrm{TEC}_{\mathrm{rel}}$ starts increasing several hours before the storm onset. Shortly after the peak, $\mathrm{TEC}_{\text {rel }}$ decreases to a negative minimum value and than slowly increases again approaching the "quiet-time" median value of zero.

The $\mathrm{TEC}_{\text {rel }}$ response differs substantially from season to season. During summer and equinox, the increase may start as early as 24 hours before the onset, in opposite to the winter storms when the increase starts about 6 hours before the onset. The increase is most pronounced during equinox, especially for intense storms, when $\mathrm{TEC}_{\text {rel }}$ rises above $20 \%$. Generally, $\mathrm{TEC}_{\text {rel }}$ remains positive during the main phase in equinox and winter for both storm classes. During first-class summer storms, $\mathrm{TEC}_{\mathrm{rel}}$ starts increasing long before the onset and remains positive for only a relatively short period of 4-5 hours after the onset. In contrast, during winter storms, the $\mathrm{TEC}_{\text {rel }}$ becomes positive only a few hours before the onset but remains positive throughout the main phase and well into the recovery phase (up to $+24 \mathrm{ST}$ ). In the latter case, the behaviour is influenced by a number of storms with gradual onset, some entirely positive storms, and data gaps.

Both the positive and negative TEC deviations from the quiet behaviour are more pronounced during intense storms. The median positive values may well exceed $+25 \%$ and drop well below $-40 \%$. During moderate storms, the TEC response is milder with positive $\mathrm{TEC}_{\text {rel }}$ peaking at $+20 \%$ and falling into the negative 20's per cent during summer.

An interesting observation is the repeated occurrence of positive and negative disturbances every 24 hours or so (at 42-44ST and again at 66-68ST hrs) during the first-class winter and summer storms. It is clearly seen in winter and can be due to local time effects, various lengths of the recovery phases, alternating atmospheric circulation, or other drivers. 


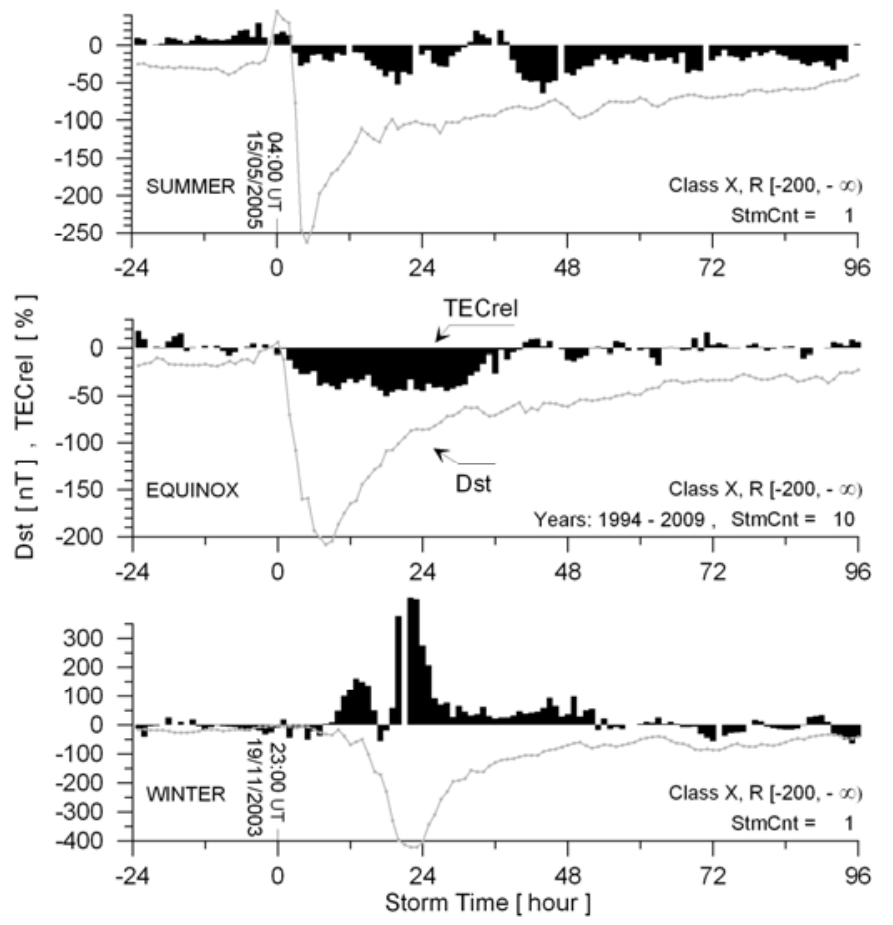

Fig.3. GPS TEC relative deviations $\left(\mathrm{TEC}_{\mathrm{rel}}\right)$ from 27-day medians during geomagnetic storms of class $\mathrm{X}$ in equinox (middle panel) for the site of the IGS station DOUR $\left(4.6^{\circ} \mathrm{E}, 50.1^{\circ} \mathrm{N}\right)$ based on data from the 19942009 period. The summer storm of 15/05/2005 and the winter storm of 20/11/2003 are presented in the top and bottom panels respectively.

The results for "extreme" geomagnetic storms are presented in Fig.3. The majority of the events occurred during equinox months and only a couple of events were recorded during solstice months. In general, the $\mathrm{TEC}_{\mathrm{rel}}$ behaviour during extreme events is similar to the one during first-class events. There are, however, some obvious differences. During equinox, the positive phase is less pronounced and the negative phase starts immediately after the storm onset. There is also an increase in $\mathrm{TEC}_{\mathrm{rel}}$ at the end of the recovery phase. In the winter storm case (20/11/2003) the positive phase is much stronger and longer lasting.

As noted before, the TEC storm time behaviour varies with latitude. The CODE's IGS TEC data from class-I and class-II storm events are used here to demonstrate the latitudinal variation in this behaviour in the range between $30^{\circ}$ and $80^{\circ} \mathrm{N}$ along the $0^{\circ} \mathrm{E}$ meridian. The results are summarised in Fig.4 where $\mathrm{TEC}_{\text {rel }}$ is plotted (colour code used) with respect to storm time (the horizontal X-axis) and latitude (the Y-axis).

During summer, the positive phase is relatively weak; the peak is about $10-15 \%$ and occurs around the onset. It is also short lived, especially at high latitudes, where the negative phase starts shortly after the onset. The negative phase at lower latitudes starts a few hours later (around +12ST at $30^{\circ}-40^{\circ} \mathrm{N}$ ). The negative phase in summer is noticeably longer than in equinox but shorter than in winter.

During equinox, the positive phase is well defined and stronger than in summer for both classes of storms. Although the negative phase is evident in all seasons and latitudes, it is clearly the strongest and shortest in equinox.

During winter, the positive phase is well pronounced for both classes, particularly at high latitudes where the increase may well exceed 50\%. The peak occurs in the first 12 hours after onset at higher latitudes and a couple of hours later at lower latitudes. The peak is obviously not so pronounced in the middle of the latitudinal range, but it still measures $20-25 \%$ at $50^{\circ} \mathrm{N}$ (which is in agreement with the DOUR measurements on Fig.2). For class-I events, the positive phase is longer lasting at higher latitudes, for example in the latitudinal band of $55^{\circ}-65^{\circ} \mathrm{N}$ it is maintained (to varying levels) well through the 60ST hour. For class-II events, the positive phase is again well pronounced at around $60^{\circ} \mathrm{N}$ although it is relatively shorter. 


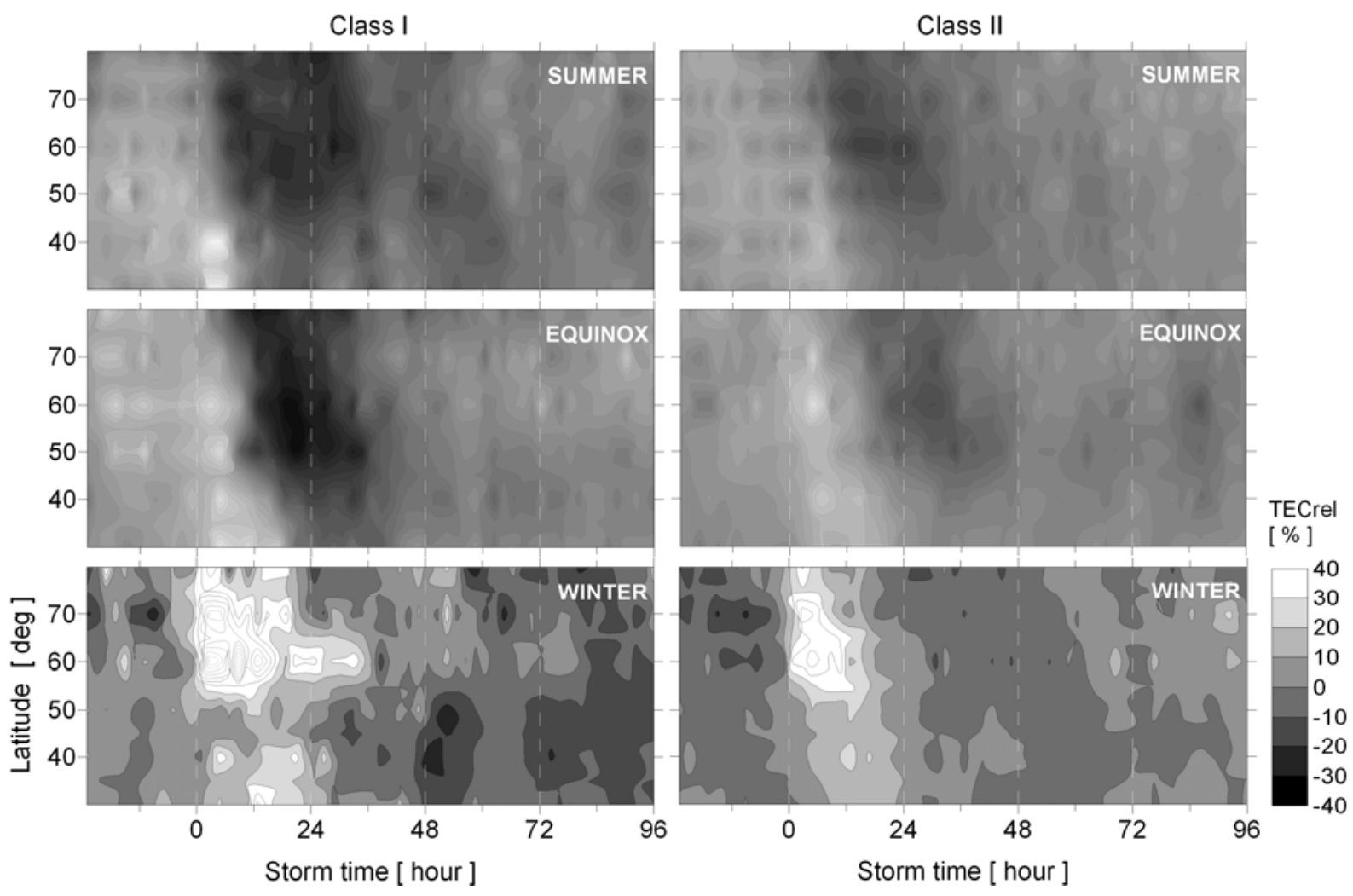

Fig.4. Latitude $\left(0^{\circ} \mathrm{E}, 30^{\circ}-80^{\circ} \mathrm{N}\right)$ vs storm time dependence of the GPS TEC relative deviation $\left(\mathrm{TEC}_{\mathrm{rel}}\right)$ from $27-$ day medians during class I (left panels) and class II (right panels) storms in summer (top), equinox (middle), and winter (bottom) based on IGS data from the 1998-2009 period.

\section{Discussion}

There are several important issues related to the TEC storm time behaviour, such as the seasonal and local time effects, propagation of ionospheric perturbations and associated latitudinal effects, positive/negative storm phases and repeated positive-negative variations.

As shown in the previous section, there are substantial seasonal differences in the TEC response. Quite often, in case studies, only winter and summer storms are considered to represent the strongest seasonal differences. Here, the equinox periods are considered very important and are also included in the analysis because several studies have already established that geomagnetic activity has a seasonal variability such that geomagnetic storms are both more intense and more numerous during equinoxes than during solstices (e.g. Hakkinen et al., 2003).

Several mechanisms have been proposed (e.g. Proelss, 1980, 1984, 1991, 1995; Fuller-Rowell et al., 1994, 1996; Buonsanto, 1999; Liou et al., 2005; and the references therein) to explain the positive and negative storm effects, and their seasonal and local-time variations, at middle latitudes. It has long been recognised that the ionospheric response during geomagnetic storms is determined mainly by dynamics (meridional winds) and composition changes. The positive phase is explained with the effect of the thermospheric winds reducing the ion loss and increasing the ion production during daytime, plasma uplifting due to thermospheric winds or electric fields, neutral gas downwelling that decreases the recombination rate, etc. Positive storm effects occur, in general, more often in winter than in summer. The negative phase is commonly explained with changes of the thermospheric composition due to thermospheric heating that pushes up molecular gases, increasing the $\mathrm{N}_{2} / \mathrm{O}$ density ratio and the ion loss rate in general, thus leading to decreased ionospheric plasma density and TEC. Negative storm effects prevail in summer.

During geomagnetic storms, enhancements in the solar wind energy cause large perturbations in the polar ionosphere and thermosphere. High-latitude electric field, precipitation of energetic particles, and plasma convection, are some of the powerful driving forces behind the highly dynamic processes in this region. As a result, significant ionospheric perturbations (including strong plasma 
density and TEC variability) are observed in this region that then propagate in equatorward direction, the speed and extent of this penetration depending on season and local time. The velocity is estimated to be in the order of 400-900 meters per second and theoretically, due to the reduced ion drag during night, the propagation is faster and more extensive in the night-time rather than in the day-time hemisphere (Kutiev et al., 1998; Stankov et al., 2006). The propagation of the ionospheric disturbances is influenced also by the observed storm-time expansion of the auroral oval towards midlatitudes (Afraimovich et al., 2009)

Repeated positive and negative disturbances in the $\mathrm{TEC}_{\text {rel }}$ behaviour during the recovery phase have been detected. Similar oscillating behaviour, appearing outside the initial and main phases of geomagnetic storms, have also been reported for the Asian sector (Kutiev et al., 2005) and explained with alternative changes in the atmospheric circulation, resulting in the upward and downward movement of the equatorial ionosphere. Post-storm enhancement (PSE) in TEC is another observed feature (Kutiev et al., 2005; 2006) due to electro-magnetic drift effects of the convection electric field penetrating deep into the low/equatorial latitude ionosphere.

Most of the PSE events appear to depend on local time (late afternoon to early evening hours) which raises the important question of whether and how storm-time TEC changes depend on local time. The TEC response to geomagnetic forcing does indeed depend on local time (e.g. Proelss, 1984; Fuller-Rowell et al., 1994; Kutiev et al., 2005). If the storm onset is during daytime, TEC increases above the median level until sunset when ionisation depletes and a negative disturbance is induced. If the storm starts during nighttime, the relative TEC starts decreasing immediately after the onset. Similar local time dependence has been observed in the foF2 response (Kutiev and Muhtarov, 2001). It is clear therefore that such local time-dependent changes in TEC should also be addressed in further statistical analyses when more data become available from storm events.

\section{Conclusion}

TEC measurements from local and European IGS stations have been used to deduce the relative TEC variations during the geomagnetic storms of the latest solar activity cycle. The superposed epoch analysis revealed some consistent features in the storm time behaviour during different seasons and latitudes. During intense storms, the relative TEC deviations show generally stronger positive and negative phases. The most pronounced positive phase is observed during winter. The strongest and shortest negative phase is detected during equinox. Both, the positive and negative effects propagate from higher to lower latitudes. Further measurements and analyses are needed to properly assess the local time variability of the storm-time effects.

For many GNSS applications (e.g. Network RTK), it is more important to concentrate on monitoring and specifying the local/regional ionospheric behaviour and effects, e.g. the TEC response to geomagnetic activity, rather than on the global ionosphere features. Several applications are envisaged. A new procedure is being developed for TEC forecasting, in which the TEC temporal behaviour is considered as composed of a periodic component and a random component. The periodic component represents the average (annual, diurnal) non-disturbed variation, whereas the random component represents variations inflicted by strong changes in the solar/geomagnetic activity. First, the TEC median behaviour is predicted by using the latest value obtained from real-time GNSS measurements and by estimating the forward gradient from an ionospheric climatological model. Immediately after that, the median prediction is corrected for the influence of the 'background' level of geomagnetic activity. During geomagnetic storms however, the TEC relative deviation from its mean/median value is much stronger tied to the storm time and this dependence was proved to vary considerably with season and latitude. Therefore, in the final step of the forecast, the TEC median prediction is corrected for storm-time changes. Possible operational applications include ionospheric/space weather monitoring, research, and improving GNSS-based communication/navigation system performance.

\section{Acknowledgements}

This research is funded by the Royal Meteorological Institute (RMI) via the Belgian Solar-Terrestrial Centre of Excellence (STCE). GNSS data provided by the International GNSS Service (IGS). 


\section{References}

Afraimovich, E. L., Astafyeva, E.I., Zhivetiev, I.V. Solar activity and global electron content. Doklady Earth Sciences 409A(6), 921- 924, doi:10.1134/S1028334X06060195, 2006.

Afraimovich, E.L., Astafyeva, E.I., Demyanov, V.V., Gamayunov, I.F. Mid-latitude amplitude scintillation of GPS signals and GPS performance slips. Adv. Space Res. 43(6), 964-972, doi:10.1016/j.asr.2008.09.015, 2009.

Akasofu, S.-I., Chapman, S. Solar-Terrestrial Physics. Oxford University Press, Oxford, 901 pp., 1972.

Araujo-Pradere, E.A., Fuller-Rowell, T.J., Spencer, P.S.J. Consistent features of TEC changes during ionospheric storms. J. Atm. Sol.-Terr. Phys. 68(16), 1834-1842, doi:10.1016/j.jastp.2006.06.004, 2006.

Astafyeva, E.I., Afraimovich, E.L., Oinats, A.V., Yasukevich Y.V., Zhivetiev, I.V. Dynamics of global electron content in 1998-2005 derived from global GPS data and IRI modelling. Adv. Space Res. 42(4), 763-769, doi:10.1016/j.asr.2007.11.007, 2008.

Beutler, G., Rothacher, M., Schaer, S., Springer, T.A., Kouba, J., Neilan, R.E. The International GPS Service (IGS): An interdisciplinary service in support of Earth sciences. Adv. Space Res. 23(4), 631-653, doi:10.1016/S0273-1177(99)00160-X, 1999.

Buonsanto, M.J. Ionospheric storms - a review. Space Science Reviews, 88, 563-601, 1999.

Fuller-Rowell, T.J., Codrescu, M.V., Moffett, R.J., Quegan, S. Response of the thermosphere and ionosphere to geomagnetic storms. J. Geophys. Res. 99(A3), 3893-3914, doi:10.1029/93JA02015, 1994.

Fuller-Rowell, T.J., Codrescu, M.V., Rishbeth, H., Moffett, R.J., Quegan, S. On the seasonal response of the thermosphere and ionosphere to geomagnetic storms. J. Geophys. Res. 101(A2), 23432353, doi:10.1029/95JA01614, 1996.

Gonzalez, W.D., Joselyn, J.A., Kamide, Y., Kroehl, H.W., Rostoker, G., Tsurutani, B.T., Vasyliunas, V.M. What is a geomagnetic storm? J. Geophys. Res. 99, 5771-5792, doi:10.1029/93JA02867, 1994.

Hakkinen, L.V.T., Pulkkinen, T. I., Pirjola, R.J., Nevanlinna, H., Tanskanen, E.I., Turner, N.E. Seasonal and diurnal variation of geomagnetic activity: Revised Dst versus external drivers. J. Geophys. Res. 108(A2), 1060, doi:10.1029/2002JA009428, 2003.

Hargreaves, J.K. The solar-terrestrial environment. Cambridge University Press, Cambridge, 1992.

Hernandez-Pajares, M., Juan, J.M. Sanz, J., Orus, R., Garcia-Rigo, A., Feltens, J., Komjathy, A., Schaer, S.C., Krankowski, A. The IGS VTEC maps: a reliable source of ionospheric information since 1998. J. Geodesy 83(3), 263-275, doi:10.1007/s00190-008-0266-1, 2009.

Ho, C.M., Mannucci, A.J., Lindqwister, U.J., Pi, X., Tsurutani, B.T. Global ionosphere perturbations monitored by the Worldwide GPS Network. Geophys. Res. Lett. 23(22), 3219-3222, doi:10.1029/96GL02763, 1996.

Ho, C.M., Mannucci, A. J., Sparks, L., Pi, X., Lindqwister, U.J., Wilson, B.D., Iijima, B.A., Reyes, M.J. Ionospheric total electron content perturbations monitored by the GPS global network during two northern hemisphere winter storms. J. Geophys. Res. 103(A11), 26409-26420, doi:10.1029/98JA01237, 1998.

Hocke, K. Oscillations of global mean TEC. J. Geophys. Res. 113, A04302, doi:10.1029/2007JA012798, 2008.

Hofmann-Wellenhof, B., Lichtenegger, H., Wasle, E. GNSS-Global Navigation Satellite Systems: GPS, GLONASS \& more. Springer, Vienna, 516 pp., 2008.

Jodogne, J.C., Stankov, S.M. Ionosphere-plasmasphere response to geomagnetic storms studied with the RMI-Dourbes comprehensive database. Ann. Geophysics 45(5), 629-647, 2002.

Kutiev, I., Muhtarov, P., Bradley, P. Penetration of ionospheric disturbances into the European region during geomagnetic storms. Adv. Space Res. 22(6), 865-867, 1998.

Kutiev, I., Muhtarov, P. Modeling of midlatitude $\mathrm{F}$ region response to geomagnetic activity. J. Geophys. Res. 106, 15501-15510, doi:10.1016/S0273-1177(98)00114-8, 2001.

Kutiev, I., Watanabe, S., Otsuka, Y., Saito, A. Total electron content behavior over Japan during geomagnetic storms. J. Geophys. Res., 110, A01308, doi:10.1029/2004JA010586, 2005. 
Kutiev, I. Otsuka, Y. Saito, A. Watanabe, S. GPS observations of post-storm TEC enhancements at low latitudes. Earth, Planets and Space 58, 1479-1486, 2006.

Liu, L., Wan, W., Ning, B., Zhang, M.L. Climatology of the mean total electron content derived from GPS global ionospheric maps. J. Geophys. Res. 114, A06308, doi:10.1029/2009JA014244, 2009.

Liou, K., Newell, P.T., Anderson, B.J., Zanetti, L., Meng, C.I.. Neutral composition effects on ionospheric storms at middle and low latitudes. J. Geophys. Res. 110, A05309, doi:10.1029/2004JA010840, 2005.

Mannucci, A. J., Tsurutani, B.T. , Abdu, M.A., Gonzalez, W.D., Komjathy, A., Echer, E., Iijima, B.A., Crowley, G., Anderson, D. Superposed epoch analysis of the dayside ionospheric response to four intense geomagnetic storms. J. Geophys. Res. 113, A00A02, doi:10.1029/2007JA012732, 2008.

Mendillo, M. A study of the relationship between geomagnetic storms and ionospheric disturbances at mid latitudes. Planet. Space Sci. 21, 349-358, 1973.

Proelss, G.W. Storm-induced changes in the thermospheric composition at middle latitudes. Planet. Space Sci. 35, 807- 811, doi:10.1016/0032-0633(87)90041-9, 1980.

Proelss, G.W. Local time dependence of magnetic storm effects on the atmosphere at middle latitudes. Ann. Geophysicae 2, 481-485, 1984.

Proelss, G.W. Thermosphere-ionosphere coupling during disturbed conditions. J. Geomagn. Geoelectr. 43, 537-549, 1991.

Proelss, G.W. Ionospheric F-region storms. In: Volland, H. (Ed.), Handbook of Atmospheric Electrodynamics, Volume II, CRC Press, Boca Raton, 195-248, 1995.

Schaer, S., Beutler, G., Rothacher, M., Springer, T.A. Global Ionosphere Maps Based On GPS Carrier Phase Data Routinely Produced by the CODE Analysis Center. EOS Transactions, 77 (12), p.71, 1996.

Schaer, S. Mapping and predicting the Earth's ionosphere using the global positioning system. Geodaetisch-geophysikalische Arbeiten in der Schweiz, Volume 59, Schweizerische Geodaetische Kommission, Zurich, 1999.

Stankov, S.M., Kutiev, I.S., Jakowski, N., Wehrenpfennig, A. GPS TEC forecasting based on autocorrelation analysis. Acta Geod. Geophys. Hung. 39(1), 1-14, doi:10.1556/AGeod.39.2004.1.1, 2004.

Stankov, S.M., Jakowski, N. Indexing the local ionospheric response to magnetic activity by using total electron content measurements. Acta Geod. Geophys. Hung. 41(1), 1-15, doi:10.1556/AGeod.41.2006.1.1, 2006.

Stankov, S.M., Jakowski, N., Tsybulya, K., Wilken, V. Monitoring the generation and propagation of ionospheric disturbances and effects on GNSS positioning. Radio Sci. 41, RS6S09, 2006.

Stankov, S.M., Jakowski, N. Ionospheric effects on GNSS reference network integrity. J. Atm. Sol.Terr. Phys. 69(4-5), 485-499, doi:10.1016/j.jastp.2006.08.008, 2007.

Stankov, S.M., Warnant, R., Stegen, K. Trans-ionospheric GPS signal delay gradients observed over mid-latitude Europe during the geomagnetic storms of October-November 2003. Adv. Space Res. 43(9), 1314-1324, doi:10.1016/j.asr.2008.12.012, 2009.

Sugiura, M. Hourly values of equatorial Dst for the IGY. Ann. International Geophysical Year 35(9), Pergamon Press, Oxford, 1964.

Warnant, R. Detection of irregularities in the total electron content using GPS measurements application to a mid-latitude station. Acta Geod. Geophys. Hung. 33(1), 121-128, 1998.

Warnant, R., Pottiaux, E. The increase of the ionospheric activity as measured by GPS. Earth, Planets, and Space 52(11), 1055-1060, 2000.

Warnant, R., Lejeune, S., Bavier, M. Space Weather influence on satellite based navigation and precise positioning. in: Lilensten, J. (Ed.) Space Weather - Research towards Applications in Europe, Springer, 129-146, 2007. 